\title{
DC-DC converter for photovoltaic powered battery charger
}

\author{
ABSTRACT \\ Purpose \\ The purpose of this study is to show in power-voltage curve, a unique maximum power point \\ (MPP) is existed which has the maximum power. \\ Design/methodology/approach \\ This paper presents a MPP tracker algorithm for a standalone system includes DC-DC buck \\ converter and battery storage. \\ Findings \\ By using this algorithm, the maximum available power is achieved and simultaneously, the \\ battery is charged and also protected against overcharge and discharge. The operation of the \\ proposed algorithm is evaluated in with Proteus software to be sure that it can be \\ implemented in microcontroller in reality. \\ Originality/value
}

The simulations results show that the proposed algorithm is able to detect the MPP under different irradiations. Moreover, the battery is charged during the day by PV and protected against overcharge and discharge.

Keyword: $\quad$ MATLAB; Battery charger; DC-DC converter; Maximum power point 